\title{
Preoperative embolization of skull base meningiomas: current indications, techniques, and pearls for complication avoidance
}

\author{
Nam Yoon, MD, ${ }^{1}$ Aatman Shah, MD, ${ }^{1}$ William T. Couldwell, MD, PhD, ${ }^{1}$ \\ M. Yashar S. Kalani, MD, PhD, ${ }^{1,2}$ and Min S. Park, MD',2 \\ ${ }^{1}$ Department of Neurosurgery, Clinical Neurosciences Center, University of Utah, Salt Lake City, Utah; and 2Departments of \\ Neurosurgery and Neurology, University of Virginia School of Medicine, Charlottesville, Virginia
}

Skull base meningiomas are technically challenging tumors to treat because of their deep vascular supply that can preclude early devascularization during resection. Preoperative embolization of these arterial feeders is thought to decrease blood loss and facilitate resection; however, given the complex and varied anatomy of these skull base lesions, preoperative embolization is not without risk. It is essential for both endovascular and skull base neurosurgeons to understand these risks in light of the potential benefits. The authors review the vascular anatomy of skull base meningiomas, indications for preoperative devascularization, endovascular techniques, and published results regarding embolization of these lesions.

https://thejns.org/doi/abs/10.3171/2018.1.FOCUS17686

KEYWORDS meningioma; skull base; embolization; blood supply; arterial feeders; endovascular; complications

$\mathrm{M}$ ENINGIOMAS are vascular tumors that comprise $13 \%-20 \%$ of all brain tumors, and skull base meningiomas comprise approximately $44 \%$ of all skull base tumors. ${ }^{13}$ Meningiomas can draw their vascular supply from both extracranial and intracranial circulation. Their resection can result in significant blood loss (average $200 \mathrm{ml}-2.2 \mathrm{~L}) .{ }^{11}$ Embolization has been proposed as an efficacious preoperative therapy to make resection easier with fewer surgical complications. ${ }^{37}$

Operative devascularization is an early goal of surgery. Whereas convexity meningiomas receive their blood supply from the dura mater, skull base meningiomas have deep, poorly accessible feeding vessels. The vascular pedicle is identified only after a significant portion of the lesion has been resected. Embolization may facilitate surgery and mitigate intraoperative blood loss by targeting these difficult-to-reach vascular pedicles. ${ }^{23}$

Because of the complex vascular supply of skull base meningiomas and the relatively ill-defined complication profile of preoperative embolization for this disease, there is a paucity of data to guide treatment. Thus, it is vital that neurosurgeons have a thorough understanding of the vas- cular territories feeding skull base lesions and an appreciation of outcomes of embolization of vessels at the skull base to decide whether addition of this modality benefits the patient or increases the overall risk. Here we review the indications for preoperative devascularization, endovascular techniques, vascular anatomy, and results regarding embolization of these lesions.

\section{Indications for Embolization}

Although some outcomes studies demonstrate that preoperative embolization of meningiomas decreases blood loss and facilitates tumor resection, it is difficult to draw definitive conclusions regarding the indications and usefulness of embolization because of the lack of randomized controlled trials. The entire body of literature and standards of practice are drawn from level III evidence derived from case series. The potential complications arising from embolization and the added cost of intervention have limited its use to a subset of meningiomas. The choice to pursue embolization is largely determined by the personal preference of the neurosurgeon; ${ }^{52}$ however, several attri-

ABBREVIATIONS AEA/PEAs = anterior and/or posterior ethmoidal arteries; $\mathrm{AVM}=$ arteriovenous malformation; $\mathrm{CN}=\mathrm{cranial}$ nerve; $\mathrm{ECA}=$ external carotid artery; ICA = internal carotid artery; ILT = inferolateral trunk; IMA = internal maxillary artery; $\mathrm{MHT}=$ meningohypophyseal trunk; MMA = middle meningeal artery; NBCA = N-butyl cyanoacrylate; OphA = ophthalmic artery; PVA = polyvinyl alcohol; VA = vertebral artery.

SUBMITTED November 13, 2017. ACCEPTED January 4, 2018.

INCLUDE WHEN CITING DOI: 10.3171/2018.1.FOCUS17686. 
butes are correlated with referral for embolization: large meningioma size, ${ }^{18,31}$ high vascularity, ${ }^{18,30,47,52}$ arterial supply with challenging intraoperative access, $, 8,47$ and arterial supply from the external carotid artery (ECA).$^{30}$ Latchaw $^{35}$ classified instances in which preoperative embolization could be beneficial: difficult vascular supply; edema that obfuscates the surgical plane; involvement of dural sinuses, scalp, and calvaria; and location near the eloquent cortex. Waldron et al. ${ }^{59}$ suggested exclusion criteria such as peripheral vascular disease and history of stroke, which increases the risk of complications.

\section{Embolization Devices and Agents}

Each of the embolic agents shown to be effective for vessel embolization has advocates, but the limitations of each must also be recognized. Table 1 summarizes major studies that have analyzed outcomes and complication rates related to embolization treatment of meningiomas. The overall complication rate for embolization is $0 \%-$ $20 \%$, and the success rate (percentage of successful cases without complications) is $80 \%-100 \%$.

\section{Particle Embolisates}

Solid polyvinyl alcohol (PVA) particles expand in aqueous solution and produce an inflammatory response resulting in thrombosis of vessels, making PVA an efficacious embolic agent. ${ }^{4,14,25,40}$ One retrospective study ${ }^{9}$ demonstrated that larger particles may be safer than smaller particles: of the 108 meningiomas embolized with small PVA particles (45-50 $\mu \mathrm{M}), 9$ patients $(8.3 \%)$ had complications, whereas only 1 complication $(1.1 \%)$ was reported in the 93 tumors embolized using large particles (150-250 $\mu \mathrm{M})(\mathrm{OR} 10.2,95 \%$ CI 1.3-80.7; $\mathrm{p}=0.028)$. The authors surmised that deeper penetration into the tumor vascular bed can block venous outflow and lead to hemorrhage. This trend was also seen in other studies. ${ }^{51,53}$ Thus, although PVA is generally accepted as an effective embolic agent, the variation in size and shape of PVA particles may predispose to particle aggregation and catheter obstruction. ${ }^{4}$ This can also result in large-vessel occlusion with recanalization of the capillary bed.

Microspheres have better biomechanical properties for embolization because of their uniform size, shape, and compressibility. Microspheres can temporarily compress up to $33 \%$, allowing for smooth catheter passage and delivery. ${ }^{53}$ After delivery, the microspheres return to their original diameter, allowing for durable hemostatic embolization. Empirically, microspheres have been widely used for arteriovenous malformations (AVMs), hypervascular tumors, and even benign prostatic hyperplasia. In a cohort of 55 patients with intracranial meningiomas treated with $400-\mu \mathrm{m}$ calibrated microsphere embolization, there were no complications. This outcome was statistically similar to the outcomes among the patients treated with PVA by Carli et al. ${ }^{9}$ The difference in complication rates between the microspheres and the small and large PVA particles was not significant $(\mathrm{p}=0.066$ and $\mathrm{p}=0.8$, respectively). Because of the retrospective nature of the PVA study and the differences in properties between the 2 particle agents, these 2 cohorts may not be wholly comparable. However, in another cohort, ${ }^{4}$ microspheres were found to have better distal penetration than PVA because of the inherent biomechanical advantages. Rather than forming clusters, the microspheres formed chains in smaller vessels. Although the extent of devascularization was radiographically similar, there was significantly less blood loss intraoperatively in patients treated with microspheres. Despite some conflicting data regarding the complication profile of these particle agents, the general consensus suggests that using large particles such as 400- $\mu \mathrm{m}$ calibrated microspheres or large PVA particles is safer than using smaller PVA particles and results in fewer hemorrhagic complications.

\section{Glue Embolisates}

Glue embolisates may be associated with even lower complication rates than particle agents. ${ }^{44}$ One liquid glue, $\mathrm{N}$-butyl cyanoacrylate (NBCA), was shown to have a lower risk of hemorrhage and ischemic complications compared with particle agents. ${ }^{1,26,32,61}$ The NBCA can be delivered with a broader range of microcatheters, which allows for better distal navigation compared with particle agents. ${ }^{51}$ The NBCA can enter feeding vessels simultaneously and can be administered with lower injection pressures, which may prevent intratumoral hemorrhage, a common complication of solid embolic materials. In a study of 56 patients, ${ }^{26}$ only $4(7.1 \%)$ patients treated with NBCA had transient complications, and only 1 was related to intratumoral hemorrhage. A newer supplementary technique involves the concurrent injection of 5\% dextrose in water solution through the catheter to propel NBCA deeper into the target vessels. ${ }^{2,17,18}$ In a retrospective series of various head and neck tumors (including 5 meningiomas) treated with this dextrose push technique, ${ }^{2}$ only 1 patient experienced a complication, which involved transient stroke with speech difficulty for 2 days. Use of NBCA may be limited when the microcatheter cannot be advanced close to the meningioma feeding vessels. The NBCA may obstruct the vessel proximally, with a risk of glue reflux; however, this obstruction may still be beneficial and carries a lower risk of hemorrhage than PVA embolization. ${ }^{51}$ Use of PVA may be indicated if the microcatheter tip is not close to the direct arterial feeding vessels. Although more data are needed, preliminary reports demonstrate therapeutic promise with NBCA, with a potentially improved complication profile.

\section{Liquid Embolisates}

Preliminary data suggest that using liquid embolisates may confer a lower risk of hemorrhage when compared with solid particles. In 1 cohort of 12 patients, 2 of 7 patients treated with particle embolization developed embolization-related bleeding, whereas none of the 5 patients treated with liquid embolization developed hemorrhagic complications. ${ }^{60}$ A more recent study described a combination approach in which coils, liquid embolisates, and particles were used depending on differing conditions: liquid embolisates were used when the microcatheter could be navigated close to the tumor, and particles were used when distal access was not achievable. ${ }^{54}$ Coils and balloons were used to block embolic material from entering unintended vessels. 


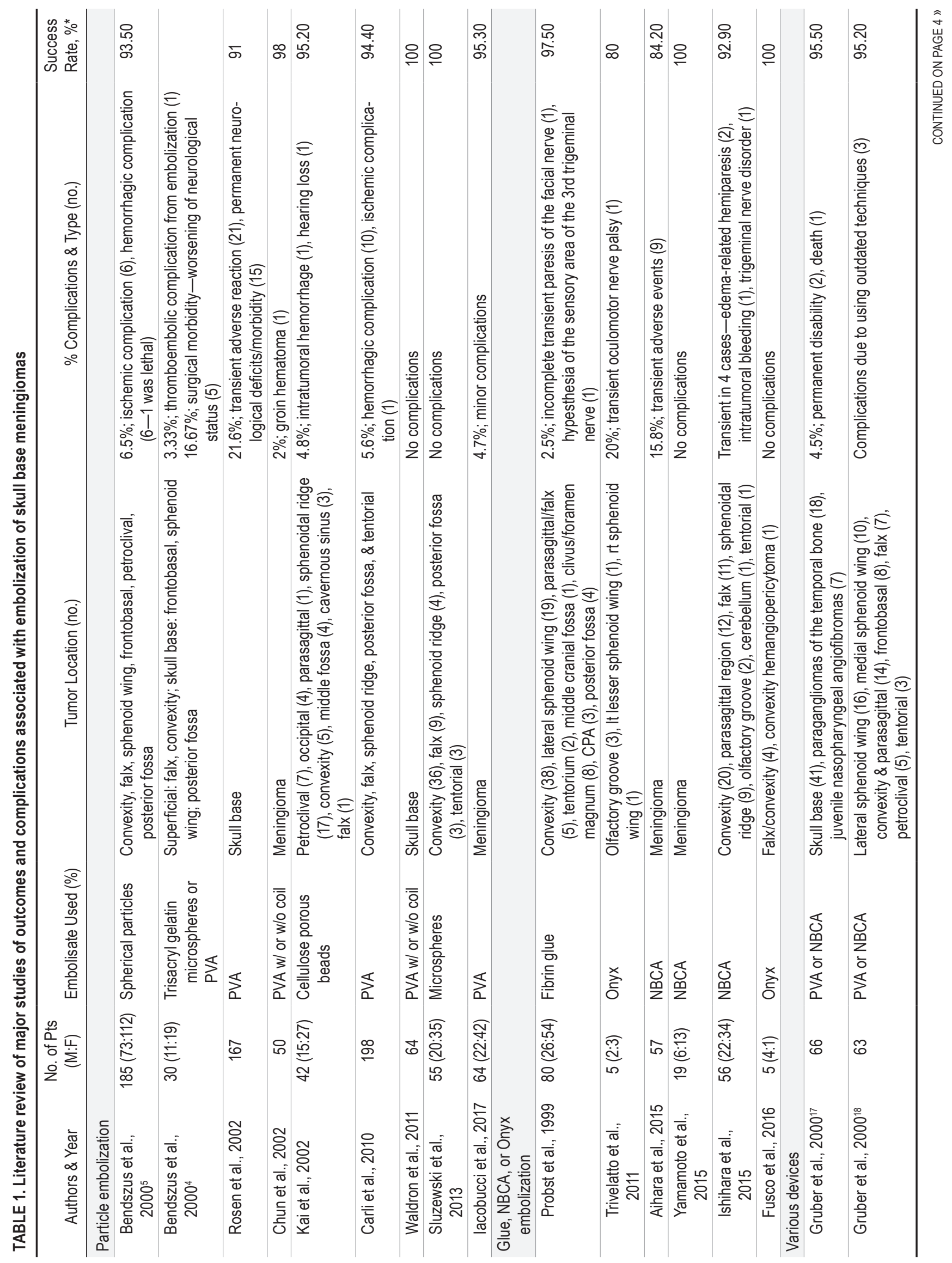




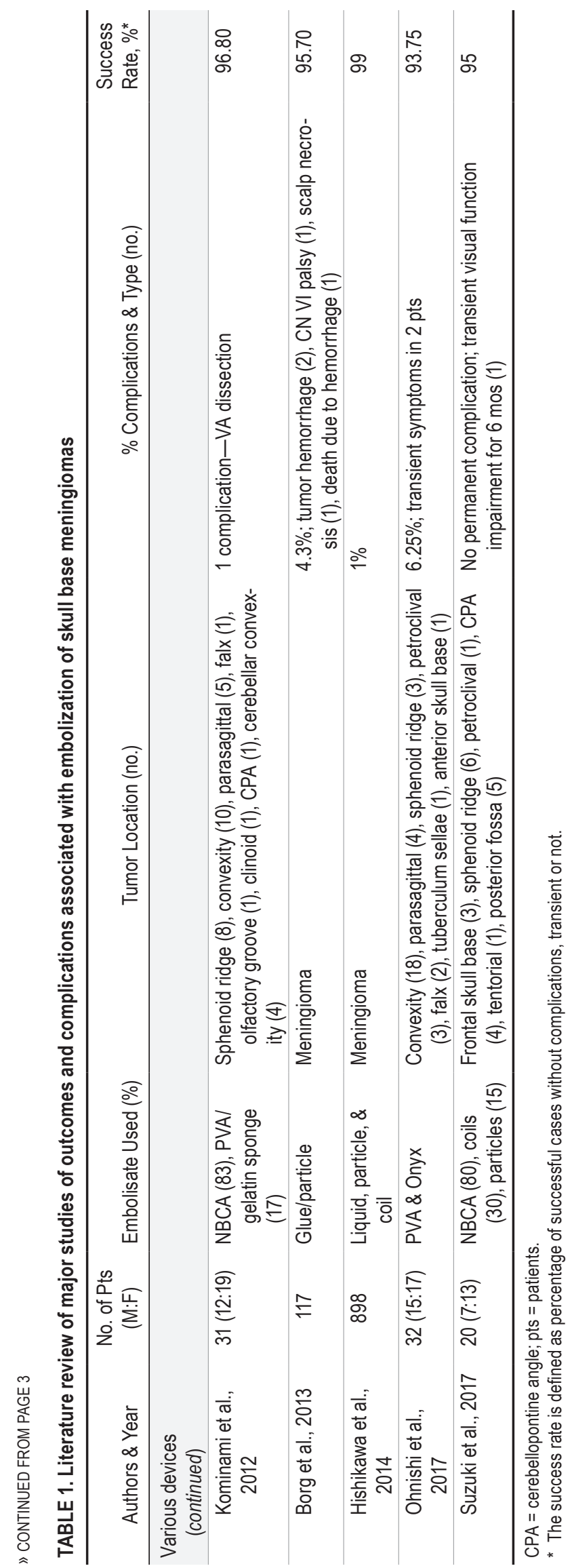

Onyx, an ethylene vinyl alcohol copolymer, has gained popularity for its success with embolization of AVMs and fistulas. ${ }^{51}$ The slower precipitation of Onyx confers advantages over other liquid agents because it can permeate deeper within the tumor vessels ${ }^{15}$ and administration can be stopped intermittently to detect nontarget embolization. ${ }^{14}$ Nevertheless, NBCA is used more often than Onyx because it has a lower complication rate and causes fewer imaging artifacts on MRI. ${ }^{40}$ There is a lack of large studies of Onyx-based embolization for meningioma. Fusco et al. ${ }^{15}$ described 4 patients who were treated with Onyx embolization, with a $100 \%$ success rate and no complications. Because of the small sample size, it is difficult to draw conclusions about the efficacy and safety profile of Onyx-based embolization of meningiomas, but the theoretical advantages lend credence for further study.

\section{Catheter Designs}

Dramatic improvements in microcatheter designs, such as flow-directed and wire-directed catheters, allow for safer embolization. In the distal cerebral vasculature, the use of wireless flow-directed catheters decreases the risk of intracerebral hemorrhage and injury to the vasculature; ${ }^{3}$ however, these catheters cannot precisely select a vessel to embolize because the catheter is directed by flow rather than by the operator. With glue agents like NBCA, the tip of the catheter should be extended as far into the pedicle as possible. With precipitates like Onyx, the catheter can be more proximal. In a series of 150 AVM embolization procedures, Aletich et al. used a hydrophilic wire in conjunction with the 1.8-Fr flow-directed microcatheter with cyanoacrylate glue. The success rate in achieving selective catheterization of the nidus improved, and the overall procedure time decreased, with only 1 complication related to wire manipulation. Although there is no literature discussing the outcomes of flow-directed catheter usage in embolizing meningiomas, their usefulness in embolizing AVMs warrants further study of their potential in meningioma treatment.

Another advancement in microcatheter design is the implementation of detachable distal tips. For example, the Apollo microcatheter (Covidien) has a highly flexible distal tip designed to be used over a 0.010 -inch microguidewire with flow-directed properties. It has a proximal radiopaque marker to delineate the detachable tip, which comes in lengths of 15,20 , or $30 \mathrm{~mm}$. This is particularly useful for Onyx embolization, where some reflux is required for better distal penetration. This "plug-and-push" technique can cause the distal microcatheter tip to become entrapped in the Onyx cast, causing microcatheter breakage or excessive traction to the blood vessels, which can cause vasospasm, stroke, or hemorrhage. ${ }^{20}$ Several groups have reported excellent results with the Apollo microcatheter when using Onyx or NBCA, ${ }^{20,41}$ with controlled detachment of the distal tip and no complications directly related to the microcatheter.

\section{Meningioma Vascular Supply Anterior and Middle Skull Base}

Anterior skull base meningiomas can have a varied 

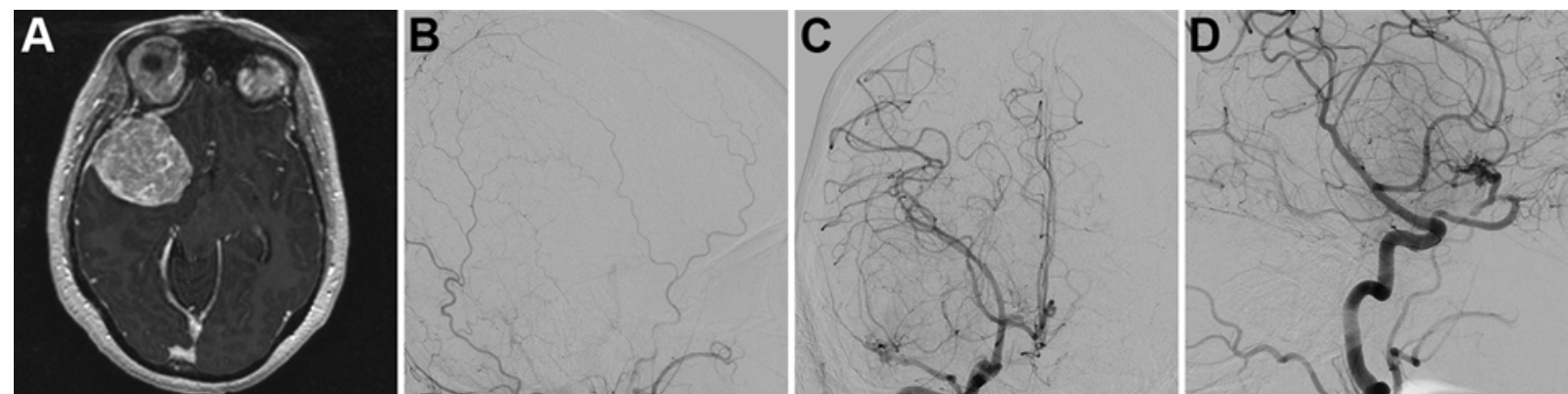

FIG. 1. Imaging obtained in a 44-year-old woman with a large right sphenoid wing meningioma mainly supplied by the recurrent meningeal branch of the OphA. On the basis of these angiograms, embolization was not attempted because of the risk of blindness. However, identification of this main feeding artery was helpful during surgery, and early devascularization of this pedicle was performed, which eased further resection. A: The tumor measures $4.6 \times 5.4 \mathrm{~cm}$ on T1-weighted contrast-enhanced MRI.

B: Right ECA angiogram demonstrates no tumor staining. C and D: Posteroanterior (C) and lateral (D) projections of the right ICA angiogram show an enlarged recurrent meningeal branch of the OphA that is the primary arterial supply to the tumor.

and complex vascular supply. The anterior and/or posterior ethmoidal arteries (AEA/PEAs) are the major arterial feeders in $<13 \%$ of skull base meningiomas. The vascular supply of meningiomas in the olfactory groove and planum sphenoidale can arise from dural, transosseous, and even pial feeders..$^{10}$ The middle meningeal arteries (MMAs) supply approximately $17 \%$ of sphenoid ridge meningiomas. ${ }^{13}$ Tumors in the anterior skull base may also be fed by arteries that supply the borders of the superior orbital fissure, such as the anterior branch of the MMA, the recurrent meningeal branches of the ophthalmic artery (OphA) and lacrimal artery (Fig. 1), the meningeal branches of the internal carotid artery (ICA), the tentorial branch of the meningohypophyseal trunk (MHT), the anterior branch of the inferolateral trunk (ILT), and the terminal branches of the internal maxillary artery (IMA). ${ }^{10}$ These collateralizations predispose meningiomas to high vascularity (Fig. 2). Waldron et al. achieved only 1 complete embolization in 55 anterior and middle fossa skull base meningioma attempts. ${ }^{59}$

Early ligation of the AEA/PEA feeders can result in less blood loss and aid in safe resection, ${ }^{57}$ but vessel wall hypertrophy and encasement in hyperostotic sclerosed foramina can cause challenges. Edematous brain tissue and large tumor size may make retraction difficult, limiting access to the feeding vessels during surgery. Endovascular embolization of these feeders may result in significant complications, such as blindness due to unintentional retrograde embolization of the OphA..$^{5}$ Trivelatto et al. ${ }^{55}$ evaluated outcomes of embolization of meningiomas via the OphA. There were no vision changes in the 5 patients, but one developed a transient oculomotor palsy. The authors claim that embolization of feeders arising from the OphA has a low chance of complication if the microcatheter is selectively placed distal to the central retinal artery to minimize reflux of the embolic agent. Their study demonstrated that proper catheter positioning technique may allow safe embolization of the OphA.

\section{Posterior Skull Base}

Because petroclival meningiomas arise from the upper two-thirds of the clivus, their location makes resection technically challenging. Feeding vessels arising from the opposite side of the approach make early open devascularization of the tumor difficult. Although this makes preoperative embolization attractive for these tumors, safe endovascular embolization can be precluded by dual blood supply from the ICA and ECA. The small and tortuous ICA feeders may arise at acute angles from the MHT
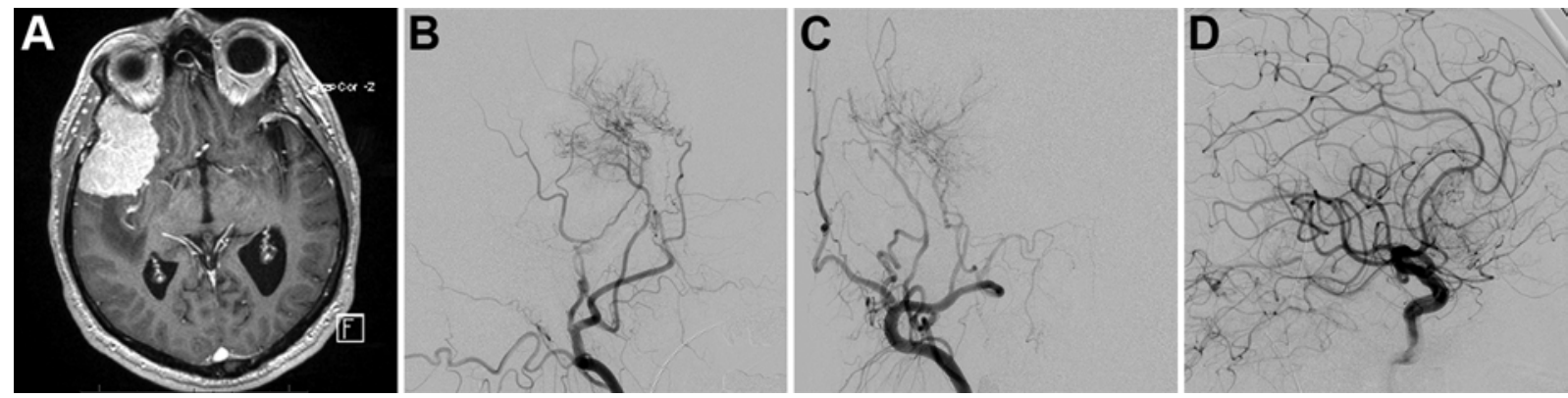

FIG. 2. Imaging obtained in a 67-year-old man with a large right sphenoid wing meningioma that had arterial supply from both ICA and ECA feeders. On the basis of these angiograms, Onyx embolization of the right MMA feeder was performed, resulting in marked reduction in tumor blush. However, complete embolization of this tumor was not safely achievable. A: The tumor measures $5.4 \times 3.6 \mathrm{~cm}$ on T1-weighted contrast-enhanced MRI. B: Right ECA angiogram demonstrates prominent arterial supply from the MMA and AEA/PEAs. C and D: Posteroanterior (C) and lateral (D) projections of the right ICA angiogram show a small amount of tumor blush, with arterial supply derived from branches of the OphA and small pial collaterals. 
and ILT. Embolization can lead to complications such as cranial nerve $(\mathrm{CN})$ palsies ${ }^{8}$ and diabetes insipidus. ${ }^{43}$ These branches can have numerous anastomotic channels crossing midline ${ }^{50}$ with tumor staining evident during contralateral ICA injections. ${ }^{33}$ The ECA feeders tend to arise from the MMA, IMA, and ascending pharyngeal artery.

Safe embolization without complications is typically incomplete, because complete embolization may involve more serious complications. Hirohata et al..$^{22}$ safely embolized 7 large petroclival meningiomas without complications but only achieved near-complete embolization in 3 . Similarly, Waldron et al..$^{59}$ only completely embolized 1 of 10 petroclival meningiomas by emphasizing complication avoidance over complete devascularization. Rosen et al. ${ }^{49}$ noted the highest risk of permanent neurological complications with petroclival meningioma embolization via the MHT (13\%) and ascending pharyngeal artery (11.8\%).

Foramen magnum meningiomas are located in the lower third of the clivus anteriorly. The involvement of the vertebrobasilar system and lower CNs introduces complexity to resection. ${ }^{12}$ The varied and intricate vascular supply to the dura mater demonstrates meningeal branches arising from the vertebral artery (VA) and the ascending pharyngeal, occipital, posterior inferior cerebellar, and posterior spinal arteries, ${ }^{7,12,46}$ which makes preoperative embolization particularly risky with regard to $\mathrm{CN}$ palsies and nontarget embolization. Waldron et al. ${ }^{59}$ only achieved incomplete embolization of the 2 foramen magnum meningiomas they treated, with one instance of CN VII palsy following embolization via the MMA and occipital artery feeders.

\section{Potentially Dangerous Anastomotic Connections and CN Supply}

The risk of unintended embolization of critical structures by way of unvisualized anastomotic connections makes it incumbent on the practitioner to have detailed knowledge of these potential anastomoses that involve the vessels of interest and to investigate potential connections thoroughly. These anastomotic connections are always present, and although they may be invisible on initial angiography, they may suddenly appear under increased intraarterial pressure during embolization. ${ }^{39}$

When embolizing tumors in the anterior fossa, the major risk is unintended occlusion of the central retinal artery via OphA collaterals, causing blindness. Retrograde flow via the OphA to the ICA can cause an embolic stroke in the distal anterior cerebral artery or middle cerebral artery territory. The proximal lacrimal artery, distal lacrimal artery, AEA/PEAs, supraorbital artery, and dorsal nasal artery branches of the OphA participate in anastomotic connections to the ECA. These arteries connect to the ECA via branches of the MMA, IMA, superficial temporal artery, and facial artery. ${ }^{42}$

Complete embolization of skull base tumors arising from the middle fossa (petrous, clival, and cavernous meningiomas) can be particularly difficult to achieve because they can have dual supply from both the ECA and the ICA circulation. The mandibular artery, caroticotympanic artery, MHT, lateral clival artery, and ILT branches of the petrous and cavernous segments of the ICA may provide arterial supply to the tumor, while being part of anastomotic connections with the ECA circulation. The ECA branches that anastomose with these arteries include branches arising from the ascending pharyngeal artery ${ }^{19}$ (Fig. 3) and the IMA ${ }^{34,56}$ (Fig. 4).

The significant anastomotic connections in the posterior fossa involve the VA. The occipital artery maintains its fetal connection to the VA through posterior anastomotic radicular branches and can sometimes be enlarged (Fig. 5), or can even be the origin of the VA itself (Fig. 6). ${ }^{38}$ The stylomastoid artery, which can arise from the occipital artery, participates in the arterial supply of the posterior fossa dura, which is also supplied by branches

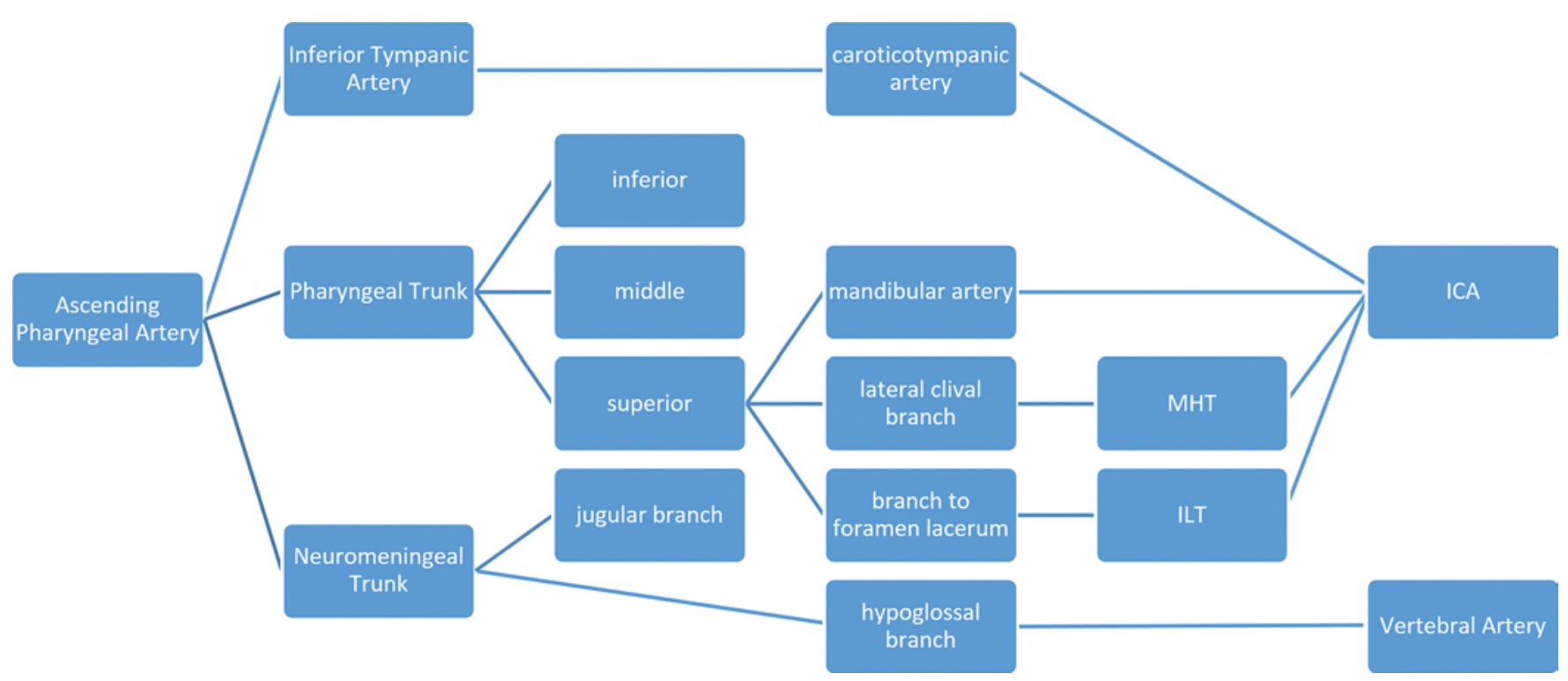

FIG. 3. Simplified schematic demonstrating the various anastomotic connections between the ascending pharyngeal artery and the ICA and VA. 


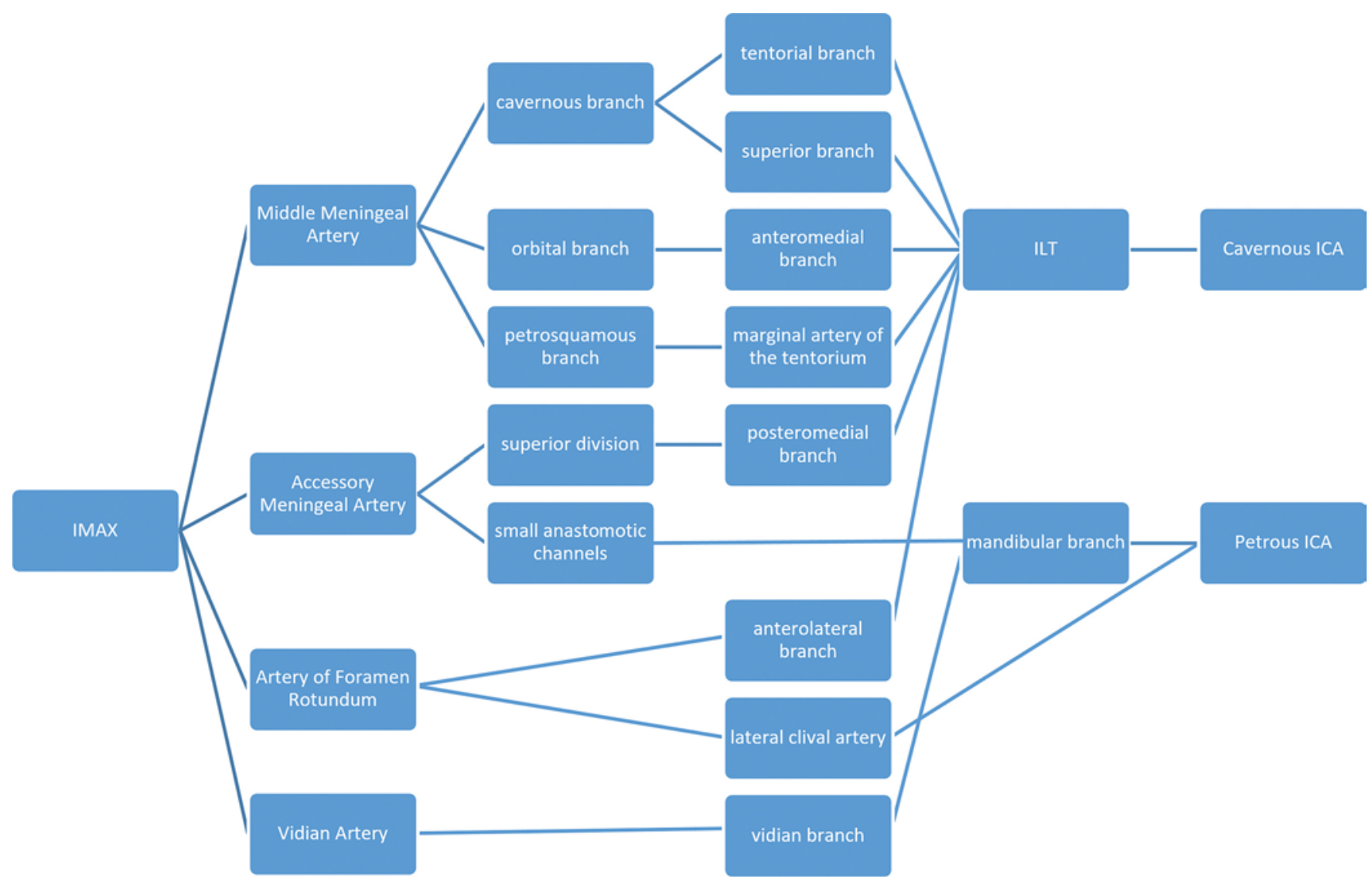

FIG. 4. Simplified schematic demonstrating the various anastomotic connections between the IMA (IMAX) branches and the ICA.

of the VA, the ascending pharyngeal artery, and the ECA (via the MMA), and ICA (via the ILT and MHT) branches. The ascending pharyngeal artery also has direct anastomotic connections with the VA via the musculospinal and prevertebral branches.

The lower CNs are at risk when targeting ECA feeders to meningiomas arising from the middle and posterior fossa. The neuromeningeal branch of the ascending pharyngeal artery is particularly important, because it is involved in the arterial supply of the foraminal segments of CNs IX-XII. The geniculate branch of CN VII is supplied by both the petrous branch of the MMA and the stylomastoid branch of the posterior auricular artery. A more detailed review of the blood supply of CNs has been described. ${ }^{16}$

\section{Published Outcomes}

There is a paucity of prospective and retrospective clinical data on the embolization of skull base meningiomas. Rosen et al. ${ }^{49}$ reported outcomes and complications in a retrospective cohort of 167 patients. The MMA was the most commonly embolized artery, with $59.6 \%$ of tumors successfully embolized via this branch. The MHT was the route of embolization in $41 \%$ of patients, whereas other arteries were embolized in $4.8 \%-11.4 \%$ of cases. There was an overall complication rate of $21.6 \%$, with $9 \%$ of the cohort suffering permanent neurological deficits. Five patients (3\%) experienced new $\mathrm{CN}$ deficits that were ex- pected based on surgical planning. Morbidity was not increased when the OphA and VA were used. Embolization of the ascending pharyngeal artery had the highest rate of temporary and permanent deficits.

Waldron et al. ${ }^{59}$ published a retrospective series of 119 skull base meningiomas referred for embolization. Feeding vessels arose from the ECA in 26 patients (22\%); the ICA in 30 (25\%); a combination of ECA, ICA, and VA in 54 (45\%); and the pial supply in $10(8 \%)$. The most common locations were the sphenoid ridge (27 patients), anterior fossa (26), tentorium (15), and petrosal ridge/clivus (14). Total devascularization following embolization occurred in 6 of 64 patients (4 with ECA supply, 2 with ICA supply), and subtotal devascularization was seen in 58 of 64 . There were no complications related to embolization. The discrepancy in complication rates between the cohorts may be due to the overall treatment strategy of the neurointerventional teams. Specifically, Waldron et al. emphasized risk avoidance over complete devascularization to reduce complication rates, but only $18 \%$ of ICA feeders were embolized. Although more data are needed, these 2 cohorts have provided significant insight into embolic adjuvant treatment for skull base vascular lesions.

\section{Discussion}

Skull base meningiomas are particularly challenging to treat because of their anatomical location and the poten- 

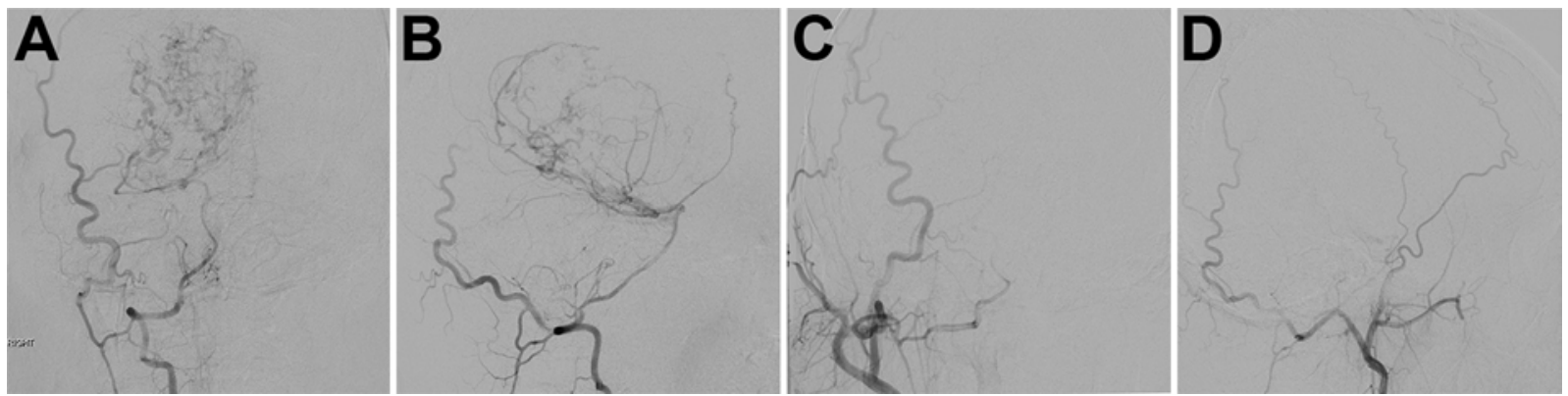

FIG. 5. Imaging obtained in a 16 -year-old boy who presented with a large right intraventricular meningioma that had arterial supply from both the middle cerebral and posterior cerebral arteries. Diagnostic angiograms clearly demonstrate an anastomotic connection between the right VA and the right occipital artery. A and B: Posteroanterior (A) and lateral $(B)$ projections of the right VA angiogram. C and D: Posteroanterior (C) and lateral (D) projections of the right ECA angiogram.

tial for a vascular pedicle opposite the surgical approach, precluding early devascularization during surgery. Raper et al. ${ }^{45}$ demonstrated that resection of skull base meningiomas was associated with higher blood loss and lower chance of gross-total resection than convexity lesions. Thus, skull base meningiomas are an attractive target for preoperative embolization. Nevertheless, the vascular supply to skull base meningiomas is quite complex and variable, with important anastomotic connections to vital neurological structures. In addition to the commonly known ECA-ICA connections, anastomoses can occur through the tumor vascular network itself. These connections may not be visible until an artery is undergoing active embolization..$^{39}$ For these reasons, aggressive embolization can be fraught with permanent postprocedural neurological deficits. Rosen et al. ${ }^{49}$ reported that $36(21.6 \%)$ patients experienced a complication, including 15 (9\%) with major neurological deficits after 24 hours, including new $\mathrm{CN}$ palsies, hemiparesis, aphasia, and blindness.

Different techniques have been proposed to help minimize the risk of embolizing unintended neurological structures. For example, a provocative microcatheter lidocaine or amytal challenge of the target vessel prior to planned embolization can help prevent unintended stroke and/or $\mathrm{CN}$ palsies..$^{24,28,29}$ Some authors have proposed using medium-sized particles $(>150 \mu \mathrm{m})$ to minimize the risk of $\mathrm{CN}$ injury, because larger particles are thought to be too large to enter and occlude the vasa nervosum supplying $\mathrm{CNs}^{35,48}$
However, larger particles may not penetrate into the tumor as effectively as smaller particles, ${ }^{58}$ and may be less effective in the setting of an intratumoral collateral network between the ECA and ICA circulation. ${ }^{27}$

Newer technology, such as angio-CT, may help prevent embolization of unintended structures by allowing the practitioner to better visualize the tumor's vascular supply. ${ }^{21}$ Microcatheters are used for superselective catheterization of target vessels, followed by the acquisition of an angio-CT. This technique may allow for identification of structures such as the retina that are not identified during routine digital subtraction angiograms. Although its use is in the experimental stages, intraarterial MR perfusion may allow quantitative evaluation of ECA versus ICA pial supply to the tumor. ${ }^{36}$ This may help surgeons better determine the benefit of embolization prior to beginning intervention.

There may be questionable benefit to incomplete devascularization of these skull base meningiomas. Bendszus et al..$^{5}$ demonstrated that only complete embolization of the meningioma resulted in decreased blood loss during resection. Borg et al. ${ }^{6}$ demonstrated that patients with partially devascularized tumors had a 3 -fold greater risk of requiring transfusion during open surgery than those with completely devascularized tumors. In tumors with both ICA and ECA supply, embolization of just the ECA feeders was effective in only $26.5 \%$ of tumors, based on decreased tumor blush on postembolization angiography. ${ }^{27}$
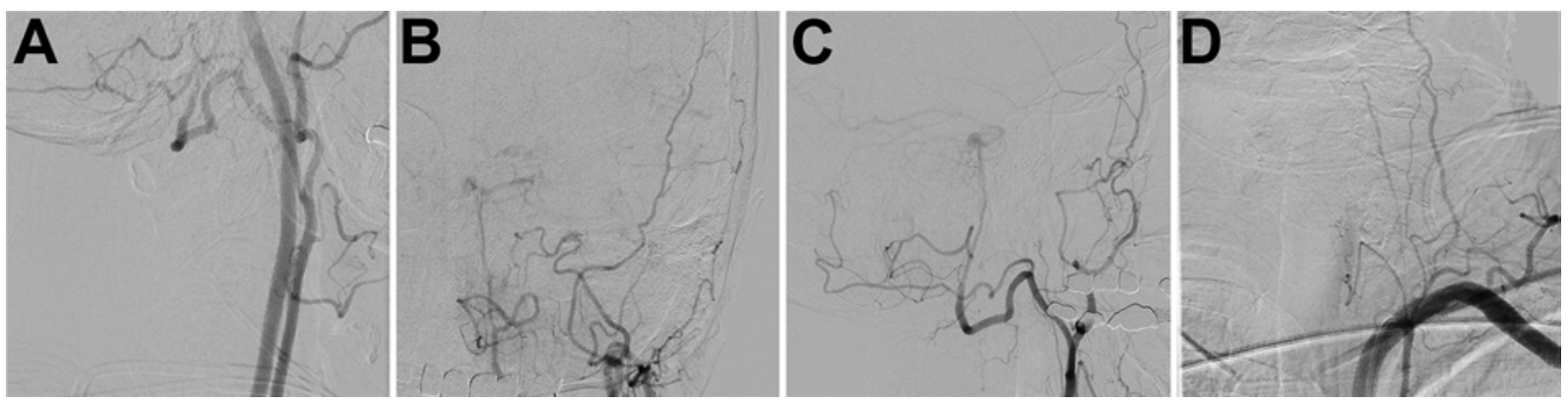

FIG. 6. Imaging obtained in a 71-year-old woman who underwent angiography for workup of a 5.1-mm basilar tip aneurysm and was found to have an anomalous origin of the left VA from the ECA. A: Lateral projection of the common carotid artery angiogram. B and C: Posteroanterior (B) and lateral (C) projections of the ECA angiogram. D: Posteroanterior projection of the left subclavian artery angiogram shows a hypoplastic left VA that terminates in proximal muscular branches. 


\section{Conclusions}

The anatomy and vascular supply of skull base meningiomas make preoperative embolization an attractive adjunct to resection; however, their complex and varied arterial supply can make safe embolization technically challenging. Subtotal embolization may not be associated with any reduction in operative blood loss, whereas aggressive embolization may be associated with serious complications. Thus, the needs of thorough devascularization of the tumor must be balanced with the attendant risks of a more aggressive approach. We advocate a conservative approach that favors complication avoidance over more aggressive devascularization. This involves avoiding any feeders arising from the ICA and using different devices based on the vascular anatomy, such as $\geq 300-\mu \mathrm{m}$ PVA particles when there is risk of CN palsy, and NBCA or Onyx only when the microcatheter is sufficiently distal to any potentially hazardous anastomotic connections.

\section{References}

1. Aihara M, Naito I, Shimizu T, Fujimaki H, Asakura K, Miyamoto N, et al: Preoperative embolization of intracranial meningiomas using n-butyl cyanoacrylate. Neuroradiology 57:713-719, 2015

2. Alaraj A, Dashti R, Mehta NK, Goodin S, Charbel FT, Aletich VA: Augmentation of N-butyl cyanoacrylate embolization of cranial, head, and neck tumors by simultaneous infusion of 5\% dextrose solution. J Neurointerv Surg 7:463-470, 2015

3. Aletich VA, Debrun GM, Koenigsberg R, Ausman JI, Charbel F, Dujovny M: Arteriovenous malformation nidus catheterization with hydrophilic wire and flow-directed catheter. AJNR Am J Neuroradiol 18:929-935, 1997

4. Bendszus M, Klein R, Burger R, Warmuth-Metz M, Hofmann E, Solymosi L: Efficacy of trisacryl gelatin microspheres versus polyvinyl alcohol particles in the preoperative embolization of meningiomas. AJNR Am J Neuroradiol 21:255-261, 2000

5. Bendszus M, Rao G, Burger R, Schaller C, Scheinemann K, Warmuth-Metz M, et al: Is there a benefit of preoperative meningioma embolization? Neurosurgery 47:1306-1312, 2000

6. Borg A, Ekanayake J, Mair R, Smedley T, Brew S, Kitchen $\mathrm{N}$, et al: Preoperative particle and glue embolization of meningiomas: indications, results, and lessons learned from 117 consecutive patients. Neurosurgery 73 (2 Suppl Operative):ons244-ons252, 2013

7. Bruneau M, George B: Classification system of foramen magnum meningiomas. J Craniovertebr Junction Spine 1:10-17, 2010

8. Capo H, Kupersmith MJ, Berenstein A, Choi IS, Diamond GA: The clinical importance of the inferolateral trunk of the internal carotid artery. Neurosurgery 28:733-738, 1991

9. Carli DF, Sluzewski M, Beute GN, van Rooij WJ: Complications of particle embolization of meningiomas: frequency, risk factors, and outcome. AJNR Am J Neuroradiol 31:152154,2010

10. Cecchini G: Anterior and posterior ethmoidal artery ligation in anterior skull base meningiomas: a review on microsurgical approaches. World Neurosurg 84:1161-1165, 2015

11. Chun JY, McDermott MW, Lamborn KR, Wilson CB, Higashida R, Berger MS: Delayed surgical resection reduces intraoperative blood loss for embolized meningiomas. Neurosurgery 50:1231-1237, 2002

12. de Oliveira E, Rhoton AL Jr, Peace D: Microsurgical anat- omy of the region of the foramen magnum. Surg Neurol 24:293-352, 1985

13. El-Fiki M: Surgical anatomy for control of ethmoidal arteries during extended endoscopic endonasal or microsurgical resection of vascular anterior skull base meningiomas. World Neurosurg 84:1532-1535, 2015

14. Elhammady MS, Peterson EC, Johnson JN, Aziz-Sultan MA: Preoperative Onyx embolization of vascular head and neck tumors by direct puncture. World Neurosurg 77:725-730, 2012

15. Fusco MR, Salem MM, Gross BA, Reddy AS, Ogilvy CS, Kasper EM, et al: Preoperative embolization of extra-axial hypervascular tumors with Onyx. J Cerebrovasc Endovasc Neurosurg 18:12-18, 2016

16. Geibprasert S, Pongpech S, Armstrong D, Krings T: Dangerous extracranial-intracranial anastomoses and supply to the cranial nerves: vessels the neurointerventionalist needs to know. AJNR Am J Neuroradiol 30:1459-1468, 2009

17. Gruber A, Bavinzski G, Killer M, Richling B: Preoperative embolization of hypervascular skull base tumors. Minim Invasive Neurosurg 43:62-71, 2000

18. Gruber A, Killer M, Mazal P, Bavinzski G, Richling B: Preoperative embolization of intracranial meningiomas: a 17-years single center experience. Minim Invasive Neurosurg 43:18-29, 2000

19. Hacein-Bey L, Daniels DL, Ulmer JL, Mark LP, Smith MM, Strottmann JM, et al: The ascending pharyngeal artery: branches, anastomoses, and clinical significance. AJNR Am J Neuroradiol 23:1246-1256, 2002

20. Herial NA, Khan AA, Suri MF, Sherr GT, Qureshi AI: Liquid embolization of brain arteriovenous malformation using novel detachable tip micro catheter: a technical report. J Vasc Interv Neurol 7:64-68, 2014

21. Hirai T, Korogi Y, Ono K, Uemura S, Yamashita Y: Preoperative embolization for meningeal tumors: evaluation of vascular supply with angio-CT. AJNR Am J Neuroradiol 25:74-76, 2004

22. Hirohata M, Abe T, Morimitsu H, Fujimura N, Shigemori M, Norbash AM: Preoperative selective internal carotid artery dural branch embolisation for petroclival meningiomas. Neuroradiology 45:656-660, 2003

23. Hishikawa T, Sugiu K, Hiramatsu M, Haruma J, Tokunaga K, Date I, et al: Nationwide survey of the nature and risk factors of complications in embolization of meningiomas and other intracranial tumors: Japanese Registry of NeuroEndovascular Therapy 2 (JR-NET2). Neuroradiology 56:139-144, 2014

24. Horton JA, Kerber CW: Lidocaine injection into external carotid branches: provocative test to preserve cranial nerve function in therapeutic embolization. AJNR Am J Neuroradiol 7:105-108, 1986

25. Iacobucci M, Danieli L, Visconti E, Maresca M, Anile C, Colosimo C, et al: Preoperative embolization of meningiomas with polyvinyl alcohol particles: the benefits are not outweighed by risks. Diagn Interv Imaging 98:307-314, 2017

26. Ishihara H, Ishihara S, Niimi J, Neki H, Kakehi Y, Uemiya $\mathrm{N}$, et al: The safety and efficacy of preoperative embolization of meningioma with N-butyl cyanoacrylate. Interv Neuroradiol 21:624-630, 2015

27. Jo KI, Kim B, Cha MJ, Choi JH, Jeon P, Kim KH: Safety and efficacy of medium-sized particle embolisation for skull-base meningioma. Clin Radiol 71:335-340, 2016

28. Kai Y, Hamada J, Morioka M, Yano S, Nakamura H, Makino $\mathrm{K}$, et al: Preoperative cellulose porous beads for therapeutic embolization of meningioma: provocation test and technical considerations. Neuroradiology 49:437-443, 2007

29. Kai Y, Hamada J, Morioka M, Yano S, Todaka T, Ushio Y: Appropriate interval between embolization and surgery in patients with meningioma. AJNR Am J Neuroradiol 23:139-142, 2002 
30. Kai Y, Hamada JI, Morioka M, Yano S, Nakamura H, Makino K, et al: Clinical evaluation of cellulose porous beads for the therapeutic embolization of meningiomas. AJNR Am J Neuroradiol 27:1146-1150, 2006

31. Kallmes DF, Evans AJ, Kaptain GJ, Mathis JM, Jensen ME, Jane JA, et al: Hemorrhagic complications in embolization of a meningioma: case report and review of the literature. Neuroradiology 39:877-880, 1997

32. Kominami S, Watanabe A, Suzuki M, Mizunari T, Kobayashi S, Teramoto A: Preoperative embolization of meningiomas with N-butyl cyanoacrylate. Interv Neuroradiol 18:133-139, 2012

33. Kunii N, Ota T, Kin T, Kamada K, Morita A, Kawahara N, et al: Angiographic classification of tumor attachment of meningiomas at the cerebellopontine angle. World Neurosurg 75:114-121, 2011

34. Lasjaunias P, Moret J, Mink J: The anatomy of the inferolateral trunk (ILT) of the internal carotid artery. Neuroradiology 13:215-220, 1977

35. Latchaw RE: Preoperative intracranial meningioma embolization: technical considerations affecting the risk-to-benefit ratio. AJNR Am J Neuroradiol 14:583-586, 1993

36. Lum MA, Martin AJ, Alexander MD, McCoy DB, Cooke DL, Lillaney P, et al: Intra-arterial MR perfusion imaging of meningiomas: comparison to digital subtraction angiography and intravenous MR perfusion imaging. PLoS One 11:e0163554, 2016

37. Manelfe C, Guiraud B, David J, Eymeri JC, Tremoulet M, Espagno J, et al: [Embolization by catheterization of intracranial meningiomas.] Rev Neurol (Paris) 128:339-351, 1973 (Fr)

38. Nasir S, Hussain M, Khan SA, Mansoor MA, Sharif S: Anomalous origin of right vertebral artery from right external carotid artery. J Coll Physicians Surg Pak 20:208-210, 2010

39. Ohata K, Nishio A, Takami T, Goto T: Sudden appearance of transdural anastomosis from middle meningeal artery to superior cerebellar artery during preoperative embolization of meningioma. Neurol India 54:328, 2006

40. Ohnishi H, Miyachi S, Murao K, Hiramatsu R, Takahashi $\mathrm{K}$, Ohnishi $\mathrm{H}$, et al: Infiltrated embolization of meningioma with dilute cyanoacrylate glue. Neurol Med Chir (Tokyo) 57:44-50, 2017

41. Paramasivam S, Altschul D, Ortega-Gutiarrez S, Fifi J, Berenstein A: N-butyl cyanoacrylate embolization using a detachable tip microcatheter: initial experience. J Neurointerv Surg 7:458-461, 2015

42. Perrini P, Cardia A, Fraser K, Lanzino G: A microsurgical study of the anatomy and course of the ophthalmic artery and its possibly dangerous anastomoses. J Neurosurg 106:142150,2007

43. Phatouros CC, Higashida RT, Malek AM, Smith WS, Dowd $\mathrm{CF}$, Halbach VV: Embolization of the meningohypophyseal trunk as a cause of diabetes insipidus. AJNR Am J Neuroradiol 20:1115-1118, 1999

44. Probst EN, Grzyska U, Westphal M, Zeumer H: Preoperative embolization of intracranial meningiomas with a fibrin glue preparation. AJNR Am J Neuroradiol 20:1695-1702, 1999

45. Raper DM, Starke RM, Henderson F Jr, Ding D, Simon S, Evans AJ, et al: Preoperative embolization of intracranial meningiomas: efficacy, technical considerations, and complications. AJNR Am J Neuroradiol 35:1798-1804, 2014

46. Rhoton AL Jr: The foramen magnum. Neurosurgery 47 (3 Suppl):S155-S193, 2000

47. Richter HP, Schachenmayr W: Preoperative embolization of intracranial meningiomas. Neurosurgery 13:261-268, 1983

48. Robinson DH, Song JK, Eskridge JM: Embolization of meningohypophyseal and inferolateral branches of the cav- ernous internal carotid artery. AJNR Am J Neuroradiol 20:1061-1067, 1999

49. Rosen CL, Ammerman JM, Sekhar LN, Bank WO: Outcome analysis of preoperative embolization in cranial base surgery. Acta Neurochir (Wien) 144:1157-1164, 2002

50. Salamon GM, Combalbert A, Raybaud C, Gonzalez J: An angiographic study of meningiomas of the posterior fossa. $\mathbf{J}$ Neurosurg 35:731-741, 1971

51. Shah A, Choudhri O, Jung H, Li G: Preoperative endovascular embolization of meningiomas: update on therapeutic options. Neurosurg Focus 38(3):E7, 2015

52. Singla A, Deshaies EM, Melnyk V, Toshkezi G, Swarnkar A, Choi H, et al: Controversies in the role of preoperative embolization in meningioma management. Neurosurg Focus 35(6):E17, 2013

53. Sluzewski M, van Rooij WJ, Lohle PN, Beute GN, Peluso JP: Embolization of meningiomas: comparison of safety between calibrated microspheres and polyvinyl-alcohol particles as embolic agents. AJNR Am J Neuroradiol 34:727-729, 2013

54. Suzuki K, Nagaishi M, Matsumoto Y, Fujii Y, Inoue Y, Sugiura $\mathrm{Y}$, et al: Preoperative embolization for skull base meningiomas. J Neurol Surg B Skull Base 78:308-314, 2017

55. Trivelatto F, Nakiri GS, Manisor M, Riva R, Al-Khawaldeh M, Kessler I, et al: Preoperative Onyx embolization of meningiomas fed by the ophthalmic artery: a case series. AJNR Am J Neuroradiol 32:1762-1766, 2011

56. Tubbs RS, Hansasuta A, Loukas M, Louis RG Jr, Shoja MM, Salter EG, et al: Branches of the petrous and cavernous segments of the internal carotid artery. Clin Anat 20:596-601, 2007

57. Ung TH, Waziri AE, Ramakrishnan VR: Preoperative ethmoid artery ligation facilitates resection of large sub-frontal meningiomas. Am J Otolaryngol 35:424-426, 2014

58. Wakhloo AK, Juengling FD, Van Velthoven V, Schumacher M, Hennig J, Schwechheimer K: Extended preoperative polyvinyl alcohol microembolization of intracranial meningiomas: assessment of two embolization techniques. AJNR Am J Neuroradiol 14:571-582, 1993

59. Waldron JS, Sughrue ME, Hetts SW, Wilson SP, Mills SA, McDermott MW, et al: Embolization of skull base meningiomas and feeding vessels arising from the internal carotid circulation. Neurosurgery 68:162-169, 2011

60. Wang HH, Luo CB, Guo WY, Wu HM, Lirng JF, Wong TT, et al: Preoperative embolization of hypervascular pediatric brain tumors: evaluation of technical safety and outcome. Childs Nerv Syst 29:2043-2049, 2013

61. Yamamoto T, Ohshima T, Nishihori M, Goto S, Nishizawa T, Shimato S, et al: Preoperative embolization of meningiomas with low-concentration n-butyl cyanoacrylate. Nagoya J Med Sci 77:347-353, 2015

\section{Disclosures}

The authors report no conflict of interest concerning the materials or methods used in this study or the findings specified in this paper.

\section{Author Contributions}

Conception and design: Park, Yoon. Acquisition of data: Yoon, Shah. Drafting the article: Yoon, Shah. Critically revising the article: Park, Couldwell, Kalani. Reviewed submitted version of manuscript: Park, Yoon. Approved the final version of the manuscript on behalf of all authors: Park.

\section{Correspondence}

Min S. Park: University of Utah, Salt Lake City, UT. neuropub@ hsc.utah.edu. 